\title{
Carbon Emissions and Stock Returns: Evidence from the Chinese Pilot Emissions Trading Scheme
}

\author{
Miao Zhang, Russell B. Gregory-Allen \\ School of Economics and Finance, Massey University, Albany, New Zealand \\ Email: r.gregory-allen@massey.ac.nz
}

How to cite this paper: Zhang, $M$. and Gregory-Allen, R.B. (2018) Carbon Emissions and Stock Returns: Evidence from the Chinese Pilot Emissions Trading Scheme. Theoretical Economics Letters, 8, 2082-2094. https://doi.org/10.4236/tel.2018.811136

Received: May 21, 2018

Accepted: August 3, 2018

Published: August 6, 2018

Copyright (c) 2018 by authors and Scientific Research Publishing Inc. This work is licensed under the Creative Commons Attribution International License (CC BY 4.0).

http://creativecommons.org/licenses/by/4.0/

\section{(c) (i) Open Access}

\begin{abstract}
In response to mounting evidence of climate change and the Kyoto Protocol, in 2011, the Chinese central government decided to build a nationwide carbon emissions scheme, beginning with seven pilot schemes launched in 2013. These pilot schemes were based on the similar European Emissions Trading Scheme. Oestreich and Tsiakas [1] examine the European scheme, finding when carbon emission allowances were granted free of charge, firms who received them (defined as "dirty" firms) outperformed the firms who did not (defined as "clean firms"), indicating that there is a significant "carbon premium." This study follows the methodology of Oestreich and Tsiakas [1] with Chinese data from the largest of the pilot schemes, the Shenzhen Pilot Emissions Trading Scheme. We find no positive, significant carbon premium but do find weak evidence of a negative premium for a special group of "very dirty" firms.
\end{abstract}

\section{Keywords}

Carbon Emissions Trading Schemes, Carbon Premium, CAPM, Fama French Three-Factor Model

\section{Introduction}

The European Union's Emissions Trading Scheme (EU ETS), the largest international greenhouse gases emissions trading system, works on a "cap-and-trade" principle. This means that a government sets a level to which factories and installations can emit greenhouse gases and these businesses must surrender the equivalent in emission allowances at the end of the compliance year. However, if they have more allowances than the cap, they can then keep them to use later or 
to sell. If they have fewer allowances than the cap, they must buy them from other companies or receive a fine.

China, for the purpose of reaching its energy-intensity reduction goal, has relied mostly on costly administrative approaches that have had only limited success. Following the EU ETS, in 2011 China decided to build a nationwide Emissions Trading Scheme. The scheme takes into consideration that different districts in China are at varied levels of economic development. To begin, in 2013 the Chinese central government approved the formation of pilot carbon trading schemes in seven regions (extended to eight in 2016). Each region has been given a certain degree of leeway in designing their own principles in regard to the schemes. Of the regions, Shenzhen is the most economically mature as, in 1979, it was the first region to implement economic reforms and the opening-up policy. It is also the largest pilot ETS in China.

On 19 December 2017, China launched a nationwide program to be in 3 stages, with actual trading not to occur until about 2020 [2]. This study is positioned at an ideal time to examine the potential effects of the ETS while the nationwide scheme is still in development.

This research report focuses on an empirical analysis of the effect of the carbon emissions in the Shenzhen Pilot Emissions Trading Scheme. Specifically, the research question of this report is: is there a carbon premium generated by the free carbon allowances that exist in stock returns? Following Oestreich and Tsiakas (2015), we describe carbon premium as the difference in returns between firms receiving those allowances and those that do not. We address this question by using the CAPM and the Fama French three-factor model and by forming different portfolios. Carbon emission allowance data and carbon intensity information are not available; hence, we have created our own criterion to distinguish high and low carbon intensity firms. We have created a "dirty" portfolio to represent the firms that have received free carbon allowances over the sample period and a "clean" portfolio to represent firms that have not received free carbon allowances. We have also constructed a special portfolio, "dirty-minus-clean", which is the equivalent of going long on the "dirty" portfolio and going short on the "clean" portfolio. The abnormal excess return of this portfolio is defined as the "carbon premium".

As discussed very eloquently in Oestreich and Tsiakas [1], who in turn base their work on Goulder, Hafstead, and Dworsky [3], the empirical analysis of this research report explains the carbon premium based on two economic mechanisms: the effect of cash flow and the effect of carbon risk.

In regard to the effect of cash flow, the cap-and-trade principle leads to an increase in the marginal cost (either actual or opportunity) required by each unit which can lead to less output, meaning spare carbon allowances which then can be sold for profit. This mechanism attributes the carbon premium to the higher profits generated by the free carbon allowance.

In addition to the effect of higher cash flow there is a secondary mechanism 
related to carbon risk. This mechanism illustrates that carbon emitting is exposed to a risk due to price uncertainty of (future) carbon allowances. In addition, policy changes, such as when carbon allowances change from being free to being charged for, can lead to further risk exposure. According to Litterman [4] and Pindyck [5], catastrophic climate change in the future would cause carbon allowance prices to be very high, leading carbon emitting firms to face further financial risks. The higher carbon risk of carbon emitting firms should be reflected in higher expected returns of these firms, thus another reason for an existing carbon premium.

In this study, we examine whether this carbon premium exists. To control for other possible factors we use two different financial risk models: CAPM and the Fama-French 3-factor model. We do not find a positive and significant premium, although we find weak evidence for a negative effect, both contrary to the findings of Oestreich and Tsiakas [1] using German data.

\section{Regulatory Background}

\subsection{Development of Regulatory Measures and the EU ETS}

On 4 June 1992, an international environmental treaty was negotiated and signed by 154 nations at the Earth Summit, The United Nations Framework Convention on Climate Change (UNFCCC). The purpose of this treaty was to get greenhouse gas emissions to a level that will not damage the earth's climate system. In order to achieve the aims of the UNFCCC, representatives from various nations continued to meet at a number of conferences between 2007 and 2016. Perhaps the most influential of these was the Paris Agreement that was signed in 2016, and the Kyoto Protocol, which introduced the methods that the signed countries must follow in order to reach their targets [6].

The idea of the carbon market originated at the Kyoto Protocol which included two commitment periods: 2008 to 2012 and 2013 to 2020. It introduced three flexible, market-based mechanisms for countries to adopt in order achieve their carbon emission goals. The first, called Joint Implementation (JI), was designed for developed countries. This mechanism runs on a baseline-and-credit system in which participants can earn Emission Reduction Units (ERUs) from each of their emission reduction projects. ERUs, also called "carbon credits", can be used to offset emitting activities, comply with regulatory emissions targets, or as voluntary measures.

The second mechanism is the Clean Development Mechanism (CDM) and is similar to JI. It was designed for developing countries and is also run as a baseline-and-credit system. The units derived from CDM projects are called Certified Emission Reductions (CERs).

The third flexible mechanism is the Emissions Trading Scheme (ETS). This mechanism runs a cap-and-trade system which is quite different from the above two. A "cap" or "limit," also called an "allowance", is set for the amount of greenhouse gases (in metric tons) that can be emitted in a certain year. An allo- 
cation amount is calculated based on the historical emissions and productivity of each participant. Participants then receive a certain number of allowances from the government. They can also buy allowances from other participants who have spare ones or buy limited amounts of international credits from emissions reduction projects around the world.

At the end of a given year, the participants must surrender their allowances to cover their emissions; if they cannot, they face a heavy fine. If they have reduced their emissions and the level falls below their cap, they can keep the spare allowances to cover their future emissions or sell them. Over time, the "cap" is reduced so that total carbon emissions fall.

\subsection{European Union Emissions Trading Scheme}

Among the three mechanisms, the ETS is the most widely used and has created the most liquid regulated carbon market, the European Union Emissions Trading Scheme (EU ETS). It includes approximately 11,500 factory installations that annually emit 2 billion tons of carbon emissions, covers $40 \%$ of total greenhouse gas emissions in all of the EU member states, and half of the carbon emissions. As a result, the European $\mathrm{CO} 2$ price is now the global benchmark price. The EU ETS was launched in 2005. The first phase ran from January 2005 to December 2007, the second phase from January 2008 to December 2012, and the third phase, which began in January 2013, will run until December 2019. In the first and second phases, governments allocated allowances to companies free of charge at the plant level, rather than the firm level. In the current third phase, allowances are being traded at auction. Oestreich and Tsiakas [1] found in the first and second phases that companies were able to profit from the free allowances, but in third phase they were not.

\subsection{Chinese Climate Policy Developments and the Chinese Pilot ETS}

In April 2006, China held the country's sixth National Environmental Protection Conference and stated that, in order to reach its energy-saving and emissions reduction goals, the country would adopt the comprehensive use of economic, technological, legal and administrative measures instead of being over-reliant on command and control regulations. In 2007, China became the first developing country to release a National Action Plan regarding climate change and published a national climate change strategy. In 2010, the government implemented measures throughout the whole country such as shutting down factories and setting electricity use limitations. These efforts, however, achieved only limited success. In 2011, the National People's Congress approved the 12th Five-Year Plan. It included a number of climate-related goals which were to be achieved by 2015. China has also put a great deal of effort into saving energy and reducing emissions through administrative regulations. However, although these efforts have led to some achievements, they have been too costly and are not efficient 
enough for long-term development. As a result, in 2011, China decided to build a nationwide Emissions Trading Scheme.

For their national emissions trading scheme, the Chinese government approved pilot schemes in Beijing, Tianjin, Hubei, Shanghai, Guangzhou, Shenzhen, and Chongqing, adding Fujian in 2016. The government purposefully selected regions which are at different stages of economic development and gave these pilot regions a certain degree of leeway to design their own schemes based on their particular circumstances. The first seven pilot ETSs were originally planned to run from 2013 to 2015 with the intention that, if a national ETS was not formed by 2015, the pilot ETSs would continue running. The Chinese Pilot ETSs are largely based on the EU ETS with allowances freely allocated to firms. There are, however, two main differences. First, the pilot schemes in China were introduced at the firm level, not the installation or factory level as in the EU. Second, the pilot schemes cover indirect emissions from electricity generated from both within and outside the regions.

Shenzhen is a special economic zone as it has China's most mature level of economic development. Therefore, the first pilot ETS was put into operation here in June 2013. The region does not have a great deal of heavy industry so the pilot ETS only covered 635 small and medium emitting firms from 26 sectors, which account for approximately $40 \%$ of the region's emissions. In June 2015, Shenzhen finished its second compliance period.

\section{Literature Review}

Research on emissions trading schemes can be divided into two general categories: first, carbon allowance price drivers, the relationship between carbon price and stock return, and carbon spot and future prices, and second, effects of ETSs on financial performance such as stock returns, firm values and profits.

In the first category, Oberndorfer [7] focused on carbon prices and financial performance, particularly in the electricity industry. The results suggest that the carbon price and the stock returns of European electricity firms are positively related, taking into account country and time-specific effects. Carraro and Favero [8] examined carbon price drivers and found that temperature, discount rate and relative fossil fuel, oil and gas prices are the determinants of carbon price on a short-term basis, whereas carbon credit supply, future regulations change, economic growth and overall allocation impact the carbon price over the long-term. Trück, Härdle, and Weron [9] conducted empirical studies to investigate the relationship between spot and future carbon emission allowance prices in the EU ETS. They found that the market was in backwardation during Phase 1 but turned to contango during Phase 2. They believe this was caused by low Eurozone interest rates, increasing surplus Phase 2 allowances, and market participants' willingness to pay a premium to hedge against rising prices in the future.

Our study focuses on the second category-studies examining the effect of trading schemes on financial performance. Chapple, Clarkson, and Gold [10] 
examined the effect of the announcement, in 2008, that an Australian national Emissions Trading Scheme would begin in 2015. They conducted an empirical study regarding the effects of the ETS announcement on the firm values of the participants. They argued that firms with more carbon intensity would have larger impacts on the stock price. They found that there is a negative relationship between firm value and carbon intensity profile. Bushnell, Chong, and Mansur [11] considered the profitability of carbon emissions trading. They examined European carbon markets and found that profitability was not only affected by compliance costs and nominal values of emission permits, but also by a firm's industry, that is, firms in carbon and electricity intensive industries had lower profitability. Chen and Lin [12] outlined five factors that affect carbon emissions changes at the provincial level. Economic output, population-scale effect and energy structure were found to have positive effects on carbon emissions growth, whereas the carbon coefficient and energy intensity were found to have negative effects. Zhang [13] illustrates the development of carbon emissions policies in China and discusses the common and differing features of the seven pilot ETSs. The study concludes that measures, such as strict compliance enforcement, education of the covered entities, the defining of both allowances as financial assets and the duration of validity, can encourage participants to join the ETS.

Oestreich and Tsiakas [1] employ a "dirty" vs. "clean" portfolio approach with data from the German stock market and the EU ETS. They illustrated that firms which received free carbon allowances from 2003-2009 generally performed better than firms that did not. They explain that the reasons for this, following a model from Goulder et al. [3], are due to the fact that the free allocation of carbon allowances brings higher cash flow to companies. Meanwhile, these companies have exposure to high carbon risk and, therefore, exhibit a higher than expected return. This model and the methodology from Oestreich and Tsiakas [1] are used in our study of Chinese data.

In summary, though the results are somewhat mixed, there is clear evidence of some relationship between trading emissions schemes, carbon prices and firm performance. Temperature, carbon credit supply and carbon intensity are all factors in determining prices, and the existence of a trading scheme seems to have an impact on the market. We extend the "dirty" vs. "clean" portfolio method to the very large and growing Chinese market.

\section{Data and Methodology}

\subsection{Data Description}

The sample period employed in this analysis is from June 2013 to August 2015 (financial data were collected from Bloomberg), beginning when the Shenzhen Pilot ETS commenced operations and ending with the latest compliance report disclosed on the official website. It includes two compliance years from the Shenzhen carbon emissions exchange, during which time all firms were receiv- 
ing carbon allowances without charge. This sample period provides the biggest range of available data for firms participating in the emissions trading scheme (Table 1).

We do not have data on carbon emissions information, such as the number of

Table 1. Sample description. The table reports monthly descriptive statistics for 26 stocks included in the Shenzhen pilot ETS and in the SZSE Component Index for the sample period June 2013 to August 2015. ME is the average market value of equity in billion Yuan over the sample period; Mean and SDev are the mean and standard deviation of monthly returns.

\begin{tabular}{|c|c|c|c|c|c|c|c|}
\hline & \multirow{2}{*}{ Company } & \multirow{2}{*}{ Ticker } & \multirow{2}{*}{ Industry } & \multirow{2}{*}{ ME } & \multirow{2}{*}{$\begin{array}{c}\text { Shares } \\
\text { outstanding }\end{array}$} & \multicolumn{2}{|c|}{ 2013-2015 } \\
\hline & & & & & & Mean & SDev \\
\hline 1 & SEIC & 000027 & Utilities & 29.258 & $3,964,491,597$ & 0.05390 & 0.10772 \\
\hline 2 & ZTE & 000063 & Technology & 60.966 & $3,397,968,631$ & 0.01812 & 0.12240 \\
\hline 3 & BYD & 002594 & $\begin{array}{c}\text { Consumer } \\
\text { Discretionary }\end{array}$ & 120.845 & $1,561,000,000$ & 0.02745 & 0.15822 \\
\hline 4 & HYTERA & 002583 & Technology & 15.838 & $1,537,852,100$ & 0.04014 & 0.15232 \\
\hline 5 & KAIFA & 000021 & Technology & 13.845 & $1,471,259,363$ & 0.03049 & 0.13777 \\
\hline 6 & MYS & 002303 & Materials & 15.978 & $1,430,400,000$ & 0.06081 & 0.20542 \\
\hline 7 & TIANMA & 000050 & Technology & 26.691 & $1,401,098,744$ & 0.02769 & 0.17742 \\
\hline 8 & $\begin{array}{l}\text { GREATWALL } \\
\text { COMPUTER }\end{array}$ & 000066 & Technology & 18.623 & $1,323,593,886$ & 0.09963 & 0.24378 \\
\hline 9 & JINJIACO., LTD. & 002191 & $\begin{array}{c}\text { Consumer } \\
\text { Discretionary }\end{array}$ & 15.326 & $1,315,496,000$ & 0.06342 & 0.12840 \\
\hline 10 & $\begin{array}{c}\text { BAUING } \\
\text { DECORATION }\end{array}$ & 002047 & $\begin{array}{c}\text { Consumer } \\
\text { Discretionary }\end{array}$ & 14.399 & $1,263,101,435$ & 0.04580 & 0.17192 \\
\hline 11 & $\begin{array}{c}\text { LXJM } \\
\text { (LUXSHARE-ICT) }\end{array}$ & 002475 & Industrials & 36.429 & $1,257,476,660$ & 0.04858 & 0.10112 \\
\hline 12 & HAN"S LASER & 002008 & Industrials & 24.287 & $1,066,120,741$ & 0.03126 & 0.11999 \\
\hline 13 & SALUBRIS & 002294 & Health Care & 29.874 & $1,046,016,000$ & 0.01753 & 0.08398 \\
\hline 14 & O-FILM & 002456 & Technology & 28.538 & $1,030,612,000$ & 0.00601 & 0.15862 \\
\hline 15 & CR SANJIU & 000999 & Health Care & 22.446 & $978,900,000$ & -0.00070 & 0.08083 \\
\hline 16 & BATIAN & 002170 & Materials & 8.215 & $876,780,499$ & 0.05397 & 0.19696 \\
\hline 17 & COSHIP & 002052 & Technology & 7.48 & $745,959,694$ & 0.02319 & 0.16520 \\
\hline 18 & SUNLORD & 002138 & Industrials & 10.588 & $740,938,814$ & 0.01999 & 0.12610 \\
\hline 19 & $\begin{array}{c}\text { LAIBAO } \\
\text { HI-TECH(SLC) }\end{array}$ & 002106 & Technology & 6.472 & $705,816,160$ & 0.00710 & 0.08823 \\
\hline 20 & $\begin{array}{c}\text { TAT FOOK } \\
\text { TECHNOLOGY }\end{array}$ & 300134 & Technology & 15.798 & $652,800,000$ & 0.08335 & 0.24823 \\
\hline 21 & SUNWODA & 300207 & Technology & 17.837 & $645,097,000$ & 0.05267 & 0.16037 \\
\hline 22 & FENDA & 002681 & $\begin{array}{c}\text { Consumer } \\
\text { Discretionary }\end{array}$ & 21.553 & $617,569,200$ & 0.11593 & 0.36402 \\
\hline 23 & WOER & 002130 & Industrials & 10.585 & $569,387,998$ & 0.05101 & 0.13286 \\
\hline 24 & EWPT & 300115 & Technology & 16.472 & $560,164,356$ & 0.03548 & 0.13754 \\
\hline 25 & SZCLOU & 002121 & Industrials & 13.293 & $476,711,700$ & 0.05429 & 0.20484 \\
\hline 26 & DEREN & 002055 & Industrials & 14.727 & $450,512,080$ & 0.05677 & 0.32178 \\
\hline
\end{tabular}


carbon allowances allocated to each firm and each firms' carbon intensity. However, at the end of each compliance year, the Shenzhen carbon emissions exchange disclosed a list of the emitting firms that finished submitting allowances and those that did not ${ }^{1}$.

We identified 26 firms that participated in the Shenzhen pilot ETS, were listed on the Shenzhen Stock Exchange with a decent stock price history, and received free carbon allowances over the sample period. This group, equally weighted, forms our "dirty" portfolio. We further identified 464 listed firms that did not receive carbon allowances and did not participate in the Shenzhen pilot ETS. This set forms our "clean" portfolio in Approach 1 described below.

We use monthly stock returns, the Shenzhen Stock Exchange Component Index (SZSE Component Index) is our market proxy, and the risk-free rate is the rate of the 10-year Chinese government bond.

\subsection{Portfolio Classification}

In the absence of actual carbon intensity data for emitting firms, we have taken three approaches to compare firms that have carbon emissions with firms that do not.

In the first approach, we have created two portfolios-a "dirty" portfolio and a "clean" portfolio, as described above for all firms with sufficient data. As these 2 portfolios are very different in size ( 26 vs. 464 firms), we also take a second approach. The dirty portfolio is made up of the same 26 firms as in the first approach, however the clean portfolio consists of 26 firms from the large clean portfolio, but matched with the 26 firms in the dirty portfolio with regard to industry, sector and market capitalization.

The third approach is the most complex. From a government announcement identifying heavy polluters in Shenzhen during the sample period, we found that 11 firms are in our dirty portfolios above. Though we don't have actual allowance and intensity data, these 11 firms can be considered as having higher carbon emissions and, therefore, as having received more carbon allowances than other emitting firms. Thus, they form the "very dirty" portfolio for this approach. The remaining 15 emitting firms form the "medium" portfolio. The other firms in the SZSE Component Index form the clean portfolio.

\subsection{Models}

Again following Oestreich and Tsiakas [1], we examine equally weighted portfolio returns based on overall means, standard deviations, and risk models from (1) CAPM and the (2) Fama-French 3-factor model. In all cases, we examine dirty, clean and "clean-dirty" portfolios.

$$
r_{j, t}-r_{f, t}=\alpha_{j}+\beta_{j}\left(r_{M, t}-r_{f, t}\right)+\varepsilon_{j, t}
$$

${ }^{1}$ For 2013 the links are $<$ http://www.cerx.cn/jystongzhi/424.htm $>$ and $<$ http://www.cerx.cn/jystongzhi/423.htm $>$. For 2014 the links are

http://www.cerx.cn/jystongzhi/1101.htm and <http://www.cerx.cn/jystongzhi/1766.htm $>$. 


$$
r_{j, t}-r_{f, t}=\alpha_{j}+\beta_{j, 1}\left(r_{M, t}-r_{f, t}\right)+\beta_{j, 2} S M B_{t}+\beta_{j, 3} H M L_{t}+\varepsilon_{j, t}
$$

where: $r_{j, t}$ is the monthly return of portfolio $j$ at time $t$, portfolio $j$ is one of the dirty, clean or dirty-minus-clean portfolios, $r_{f, t}$ is the monthly risk-free rate at time $t, r_{M, t}$ is the market portfolio, $S M B_{t}$ is the "small-minus-big" size factor, and $H M L_{t}$ is the "high-minus-low" value factor, and $\varepsilon_{j, t}$ is a normal error term.

\section{Results and Analysis}

Table 2 shows the results of the first approach using all our available firms in which there are 26 dirty firms and 464 clean firms. The carbon premium is the alpha of the dirty-minus-clean portfolio. These alphas of $0.39 \%$ and $0.33 \%$ for the CAPM and Fama French three-factor models, respectively, are positive but insignificant.

In Table 3 are the results for the second approach with matched characteristics for the dirty and clean portfolios, resulting in 26 dirty firms and 26 clean firms. In this approach, the carbon premium is a much higher $16.5 \%$ for CAPM and $16.4 \%$ for the Fama French three-factor model, but again these results are not significant.

In the third classification approach (see Table 4), we segregate the previous dirty portfolio into a "medium" portfolio and a "very dirty" portfolio. The results show that the carbon premium (alpha of the dirty-minus-clean portfolio) is negative at $-15.17 \%$ and significant, but just barely at the $10 \%$ level. Considering all the other ambiguity in our data, this is probably not sufficient to warrant a conclusion of "significant" [14]. However, we regard this as weak evidence.

Table 2. Results of the first portfolio classification approach. The "Dirty" portfolio is a portfolio of 26 firms that are included in the SZSE Component Index and received the free carbon allowance over the sample period. The "Clean" portfolio is a 464-firm portfolio included in SZSE that did not receive any carbon allowance and did not participate in the Shenzhen pilot ETS. The return of Dirty-minus-Clean portfolio is the return of the "Dirty" portfolio minus the return of the "Clean" portfolio. All portfolios are equally weighted portfolios and results are annualized. CAPM- $\alpha$ is the alpha of a CAPM regression, FF3- $\alpha$ is the alpha of the Fama-French three-factor model regression, T-statistics are in parentheses. The asterisks ${ }^{*}{ }^{* *},{ }^{* *}$ denote statistical significance at the $10 \%, 5 \%$ and $1 \%$ level respectively.

\begin{tabular}{|c|c|c|c|}
\hline Mean & SDev & CAPM- $\alpha$ & $\mathrm{FF} 3-\alpha$ \\
\hline \multicolumn{4}{|c|}{ Dirty Portfolio (26 stocks) } \\
\hline \multirow[t]{2}{*}{0.5187} & 0.3534 & 0.3680 & 0.3279 \\
\hline & & $(1.666)$ & $(1.610)$ \\
\hline \multicolumn{4}{|c|}{ Clean Portfolio (464 stocks) } \\
\hline \multirow[t]{2}{*}{0.5390} & 0.3254 & $0.3641^{*}$ & $0.3245^{\star}$ \\
\hline & & $(2.087)$ & $(2.241)$ \\
\hline \multicolumn{4}{|c|}{ Dirty-minus-Clean Portfolio } \\
\hline \multirow[t]{2}{*}{-0.0203} & 0.4173 & 0.0039 & 0.0033 \\
\hline & & $(0.046)$ & $(0.039)$ \\
\hline
\end{tabular}


Table 3. Results of the second portfolio classification approach. The "Dirty" portfolio is a portfolio of 26 firms that are included in the SZSE Component Index and received the free carbon allowance over the sample period. The "Clean" portfolio is another 26 firms with no carbon allowance allocation that matches the 26 firms in the "Dirty" portfolio by the same or the most similar industry, sector and market capitalization within the SZSE Component Index. The return of Dirty-minus-Clean portfolio is the return of the "Dirty" portfolio minus the return of the "Clean" portfolio. All portfolios are equally weighted portfolios and results are annualized. CAPM- $\alpha$ is the alpha of a CAPM regression, FF3- $\alpha$ is the alpha of the Fama-French three-factor model regression, T-statistics are in parentheses. The asterisks ${ }^{*},{ }^{*},{ }^{* *}$ denote statistical significance at the $10 \%, 5 \%$ and $1 \%$ level respectively.

\begin{tabular}{cccc}
\hline Mean & \multicolumn{1}{c}{ SDev } & CAPM- $\alpha$ & FF3- $\alpha$ \\
\hline \multirow{4}{*}{0.5187} & \multicolumn{2}{c}{ Dirty Portfolio (26 stocks) } \\
& 0.3534 & 0.368 & 0.3279 \\
& & $(1.666)$ & $(1.610)$ \\
0.3497 & \multicolumn{2}{c}{ Clean Portfolio (26 stocks) } \\
& 0.3033 & 0.2034 & 0.1635 \\
& & $(1.131)$ & $(1.093)$ \\
0.1690 & \multicolumn{2}{c}{ Dirty-minus-Clean Portfolio } \\
& 0.5760 & 0.1646 & 0.1643 \\
& & $(1.348)$ & $(1.319)$ \\
\hline
\end{tabular}

Table 4. Results of the third portfolio classification approach. The "Very Dirty" portfolio is a portfolio of 11 firms that were identified as heavy polluters among 26 firms that are included in the SZSE Component Index and receiving the free carbon allowance. The "Medium" portfolio is the remaining 15 firms among 26 firms excluding those 11 "dirty" firms. The "Clean" portfolio is a 464-firm portfolio included in SZSE that did not receive any carbon allowance and did not participate in the Shenzhen pilot ETS. The return of the Very Dirty-minus-Clean portfolio is the return of the "Very-Dirty" portfolio minus the return of the "Clean" portfolio. All portfolios are equally weighted portfolios and results are annualized. CAPM- $\alpha$ is the alpha of a CAPM regression, FF3- $\alpha$ is the alpha of the Fama-French three-factor model regression, T-statistics are in parentheses. The asterisks ${ }^{*},{ }^{* *},{ }^{* *}$ denote statistical significance at the $10 \%, 5 \%$ and $1 \%$ level respectively.

\begin{tabular}{|c|c|c|c|}
\hline Mean & SDev & CAPM- $\alpha$ & FF3- $\alpha$ \\
\hline \multicolumn{4}{|c|}{ Very Dirty Portfolio (11 stocks) } \\
\hline \multirow[t]{2}{*}{0.3686} & \multirow[t]{2}{*}{0.3117} & 0.2124 & 0.1772 \\
\hline & & $(1.185)$ & $(1.126)$ \\
\hline \multicolumn{4}{|c|}{ Medium Portfolio (15 stocks) } \\
\hline \multirow[t]{2}{*}{0.6288} & \multirow[t]{2}{*}{0.4036} & 0.4821 & 0.4383 \\
\hline & & $(1.815)$ & $(1.750)$ \\
\hline \multicolumn{4}{|c|}{ Clean Portfolio (464 stocks) } \\
\hline \multirow[t]{2}{*}{0.5390} & \multirow[t]{2}{*}{0.3254} & $0.3641^{*}$ & $0.3245^{*}$ \\
\hline & & $(2.087)$ & $(2.241)$ \\
\hline \multicolumn{4}{|c|}{ Very Dirty-minus-Clean Portfolio } \\
\hline \multirow[t]{2}{*}{-0.1705} & 0.3059 & $-0.1517^{\star}$ & $-0.1473^{\star}$ \\
\hline & & $(-2.467)$ & $(-2.349)$ \\
\hline
\end{tabular}


An important observation to note is that the mean return of the medium portfolio is almost twice that of the dirty portfolio, which is opposite our expectation that firms receiving more free carbon allowances outperform firms that receive less or no carbon allowances. Thus, we can draw the conclusion that the effect of free carbon allowances on stock returns has less of an effect than other factors; this is consistent with our other results showing little or no carbon premium.

Our main finding from the above analysis is that the free allocation of carbon emission allowances, at the initial stage of the Chinese Shenzhen pilot ETS, did not generate a carbon premium in stock returns and, in fact, the "super dirty" firms had a negative premium. This is contrary to the finding by Oestreich and Tsiakas [1]. There are a couple of potential explanations for this. First, lacking data for carbon allowances we formed portfolios based on the specific criterion, rather than the precise numbers. This may have led to obscure boundaries of the different portfolios. For example, some of the firms in the dirty portfolio may have only had small carbon emissions.

Second, the sample period for this paper starts from the beginning of the Shenzhen pilot ETS meaning that it also starts at the beginning of the Chinese ETS. Most of the participants in the Chinese carbon trading schemes joined as a result of government policies and regulations rather than from economic analysis. Furthermore, the majority of the firms in the Chinese ETS are state-owned enterprises and, as such, are compelled to join whether they are high carbon intensity firms or not, for the sake of encouraging other firms to participate. This may have affected our results in two ways. On the one hand, since some firms joined the ETS regardless of their carbon intensity, there may be some firms in the dirty portfolio that are not actually that dirty, and the carbon allowance they received may have been very low. On the other hand, there may be a number of firms in the clean portfolio with high carbon intensity that have simply not joined the ETS and, as a result, have not received allowances. Therefore, because of how the policy has been implemented in China, there may be high carbon intensity firms "hiding" in the clean portfolio and low carbon intensity firms "hiding" in the dirty portfolio, which will have distorted our results to a certain degree.

\section{Conclusions}

As a result of human activity creating huge greenhouse gas emissions and potentially catastrophic climate change, a number of measures have been taken including the Kyoto Protocol. This protocol introduced the Carbon Emissions Trading Scheme and created the carbon market that has been operating in many countries around the world. The EU ETS, which has been in operation since 2005, has finished its initial two stages and is now in its third stage in which carbon allowances are sold at auction. Oestreich and Tsiakas [1], examining the EU ETS found that, during the stages in which emitting firms received free car- 
bon allowances from governments, there was a positive and significant carbon premium present in stock returns.

Following the European experience, China decided to construct a similar nationwide carbon emissions trading scheme, beginning with pilot schemes. Our study examines the effect on returns of the largest of those, the Shenzhen pilot ETS. We have used three methods of classifying portfolios, estimating carbon premiums with CAPM and Fama French three-factor models. Our results are quite different from those of Oestreich and Tsiakas [1], with no premium found in some portfolios and negative premiums found in the "very dirty" portfolio. Our results may have been distorted due to several factors: the classification approaches used, the absence of accurate carbon intensity data, and China's compulsory carbon regulation policy.

In summary, this paper fills a gap in the literature by providing an empirical evaluation of whether firms in the Chinese ETS that received carbon emissions allowances significantly outperformed those that did not. As China has just launched the construction phase of its nationwide carbon emission trading scheme, the carbon intensity data for each firm may be disclosed and, as a result, this research could be extended.

\section{References}

[1] Oestreich, A.M. and Tsiakas, I. (2015) Carbon Emissions and Stock Returns: Evidence from the EU Emissions Trading Scheme. Journal of Banking \& Finance, 58, 294-308. https://doi.org/10.1016/j.jbankfin.2015.05.005

[2] Shi, X. (2018) China's Emissions Trading Scheme: What It Means for Australia. ACRIFacts.

[3] Goulder, L.H., Hafstead, M.A. and Dworsky, M. (2010) Impacts of Alternative Emissions Allowance Allocation Methods under a Federal Cap-and-Trade Program. Journal of Environmental Economics and Management, 60, 161-181. https://doi.org/10.1016/j.jeem.2010.06.002

[4] Litterman, B. (2013) What Is the Right Price for Carbon Emissions. Regulation, 36, 38.

[5] Pindyck, R.S. (2013) Climate Change Policy: What Do the Models Tell Us? Journal of Economic Literature, 51, 860-872. https://doi.org/10.1257/jel.51.3.860

[6] Ellerman, A.D. and Buchner, B.K. (2007) The European Union Emissions Trading Scheme: Origins, Allocation, and Early Results. Review of Environmental Economics and Policy, 1, 66-87. https://doi.org/10.1093/reep/rem003

[7] Oberndorfer, U. (2009) EU Emission Allowances and the Stock Market: Evidence from the Electricity Industry. Ecological Economics, 68, 1116-1126. https://doi.org/10.1016/j.ecolecon.2008.07.026

[8] Carraro, C. and Favero, A. (2009) The Economic and Financial Determinants of Carbon Prices. Finance aUver. Czech Journal of Economics \& Finance, 59.

[9] Trück, S., Härdle, W.K. and Weron, R. (2014) The Relationship between Spot and Futures $\mathrm{CO}_{2}$ Emission Allowance Prices in the EU-ETS. In: Gronwald and Hintermann, Eds., Emission Trading Systems as a Climate Policy Instrument Evaluation and Prospects, MIT Press, Cambridge, Massachusetts. (Forthcoming) https://ssrn.com/abstract=2137346 
https://doi.org/10.2139/ssrn.2137346

[10] Chapple, L., Clarkson, P.M. and Gold, D.L. (2013) The Cost of Carbon: Capital Market Effects of the Proposed Emission Trading Scheme (ETS). Abacus, 49, 1-33. https://doi.org/10.1111/abac.12006

[11] Bushnell, J.B., Chong, H. and Mansur, E.T. (2013) Profiting from Regulation: Evidence from the European Carbon Market. American Economic Journal: Economic Policy, 5, 78-106. https://doi.org/10.1257/pol.5.4.78

[12] Chen, Y. and Lin, S. (2015) Decomposition and Allocation of Energy-Related Carbon Dioxide Emission Allowance over Provinces of China. Natural Hazards, 76, 1893-1909. https://doi.org/10.1007/s11069-014-1576-7

[13] Zhang, Z. (2015) Carbon Emissions Trading in China: The Evolution from Pilots to a Nationwide Scheme. Climate Policy, 15, S104-S126. https://doi.org/10.1080/14693062.2015.1096231

[14] Harvey, C.R., Liu, Y. and Zhu, H. (2016) and the Cross-Section of Expected Returns. The Review of Financial Studies, 29, 5-68. https://doi.org/10.1093/rfs/hhv059 